\title{
"THE CONTRIBUTION OF INDIRECT TOPOGRAPHIC SURVEYS (PHOTOGRAMMETRY AND LASER SCANNER) AND GPR INVESTIGATIONS IN THE STUDY OF THE VULNERABILITY OF THE ABBEY OF SANTA MARIA A MARE, TREMITI ISLANDS (ITALY).,
}

\author{
Marilena Cozzolino*,1, Andrea Di Meo², Vincenzo Gentile², \\ (1) Institute for Technologies Applied to Cultural Heritage, National Council of Researches, Via Salaria Km. 29,300, \\ Monterotondo St. (Rome), Italia, ww.itabc.cnr.it \\ (2) Independent Researcher
}

Article history

Receveid October 18, 2018; accepted May 14, 2019.

Subject classification:

Abbey of Santa Maria a Mare, GPR prospections, laser scanning, photogrammetry survey, state of conservation of historic buildings.

\begin{abstract}
A proper representation of the conservation status of an Architectural Heritage constitutes a key element of knowledge in order to guarantee the success of a restoration project, the valorization and the fruition of the monument itself. In this context, an important role is played by non-invasive diagnostics and 3D metric surveys that allow acquiring data on potential structural anomalies as well as the location and extent of hidden structures inside the walls. In this paper, the results of the surveys carried out at the Abbey of Santa Maria a Mare, San Nicola, Tremiti Islands (FG, Italy) are presented. The monument is in a significant state of degradation that is testified by the damage of internal and external plaster, water infiltration, presence of molds and superficial lesions on walls and fractures on columns. In order to define restoration interventions, the structure has been analyzed in detail through the realization of 3D metric surveys (photogrammetry and laser scanner) and non-invasive geophysical surveys (Ground Penetrating Radar Technique). The use of non-destructive testing techniques at different scales has provided assessment tools for building characteristics, state of conservation and building safety.
\end{abstract}

\section{INTRODUCTION}

The Italian architectural heritage and in particular the monumental buildings and the historic centers are among the most vulnerable to earthquakes, increasing the risk of cultural losses and causing serious consequences for public safety. As highlighted by recent seismic events, the Italian cultural heritage presents widespread critical conditions and it follows the need for an urgent definition of programs for the seismic im- provement of this heritage. Given the size of the problem and considering the huge amount of goods on the territory and their priceless value, it is therefore necessary to promote prevention policies ranging from knowledge of the vulnerability of buildings, to the construction of possible damage scenarios, to the education of expert technicians, to the elaboration of consequent emergency plans (Cifani et. al 2005).

The analysis of seismic vulnerability represents a complex process articulated in different phases such as: 

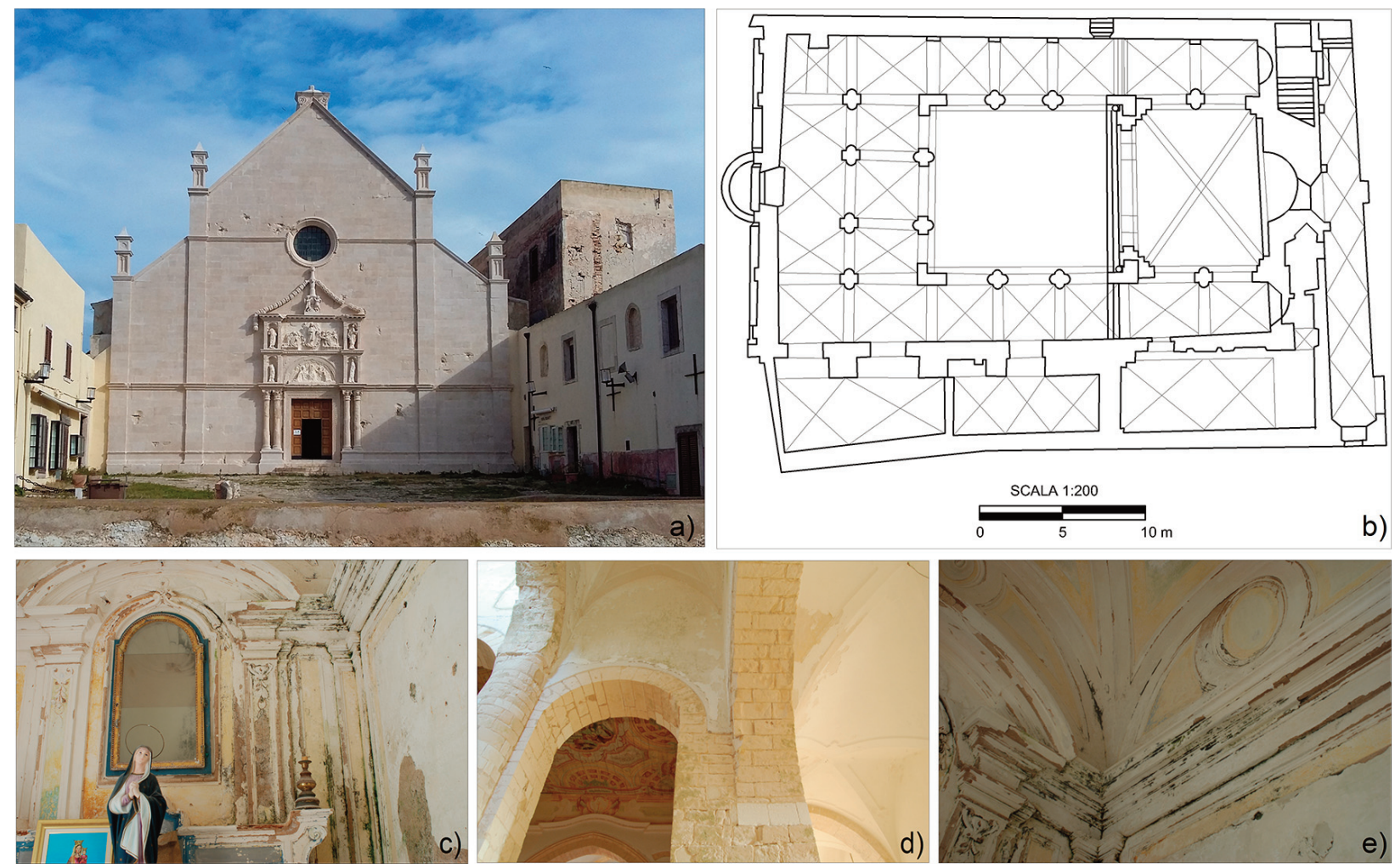

FIGURE 1. The Abbey of Santa Maria a Mare, San Nicola Island, Tremiti (Foggia, Italy): the facade (a), the plan (b) and some critical examples of degradation (c, d, e).

- collection of all available data and document analysis;

- direct investigation of the building by performing surveys;

- non-destructive and/or destructive tests on the structural elements;

- characterization of mechanical properties of materials;

- definition of the Level of Knowledge of the structure;

- analysis using numerical models created on the basis of the acquired detail data;

- critical evaluation of the results.

The critical historical analysis of the monument provides fundamental information relative to the original architectural structure, the modifications, the transformations and the alterations occurred in it over time, with particular reference to those that are dependent on historical seismic events. Only a systematic and sufficiently complete investigation can allow the various aspects of the intervention to be approached in a conscious and effective manner (Carbonara 2004). The intervention project must be preceded by a real diagnostic project that, in its elaboration and implementation, assumes the fulfillment of the diagnostic, the mapping of the elements for material quality, the graphic and photographic relief of the state of conservation of the material, the mapping of the alteration forms on which the sampling depends through the collection of significant samples to analyze in laboratory. In this work the results of 3D metric surveys and noninvasive geophysical investigations conducted at the Abbey of Santa Maria a Mare, located on the top of San Nicola lsland in the Tremiti Archipelago (Foggia, Italy), are fully presented [Cozzolino et al. 2018a]. The Benedictines built it in $1045 \mathrm{AD}$ and, even today, it preserves the original plant with a rectangular plan with three aisles that extend longitudinally from the entrance to the main altar (Figure 1a, b). The elaborate middle mosaic floor (XI-XIl century) in polychrome tiles and the painted wooden ceiling made in the 18th century to replace the dome are particularly important. The monument is in a very poor state of conservation with evident signs of deterioration as substantial detachments of plaster, water infiltration, surface damage on the walls and column fractures. This condition is due to both structural problems and to pathologies related to the degradation of the materials making up the structure (Figure 1c, d, e).

\section{METHODS AND DATA PROCESSING}

\subsection{METRIC SURVEY}

Laser scanning technology and photogrammetric 
processing of digital images enables to collect a great data amount and to provide detailed and reliable 3D surface models of the historical object [Fiani and Siani 2005, loannidis et al. 2005, Barrile et al. 2009, Vatan et al. 2009, Park et al. 2007, Remondino and Campana 2014, Selbesoglu et al. 2016, Murtiyoso and Grussenmeyer 2017, Angelini 2018]. In this work, a FARO Focus 3D MS120 laser scanner was employed for acquiring data in the complete area. The instrument allows performing scans from $0.6 \mathrm{~m}$ to $120 \mathrm{~m}$ with an error of linear distance equal $\pm 2 \mathrm{~mm}$ for a distance between scanner and object included in a range from 10 to 25 meters. The standard deviation of the values from the best-fit plan varies from $0.6 \mathrm{~mm}$ to $10 \mathrm{~m}$ with a $90 \%$ reflectivity and from $2.2 \mathrm{~mm}$ to $25 \mathrm{~m}$ with a $10 \%$ reflectivity. It has a field of view of $360^{\circ} \times 305^{\circ}$ and an integrated color digital camera with a 70 megapixel resolution. It also has a vertical visual field of $305^{\circ}$ and the horizontal one of $360^{\circ}$. The horizontal and vertical resolution is $0.009^{\circ}$. The range sensor uses a phase shift technology for measuring distances, repeating the single point measurements up to 976,000 times per second.

All the building was recorded in the internal part and on the external façade with a quality of $1 / 5$ that means one point each $5 \mathrm{~mm}$ at $10 \mathrm{~m}$. Totally, 54 laser scanner positions ( 3 exteriors and 51 inside the building) were determined during data acquisition ensuring at least three homologous points for each point cloud. Advantages of using this technology to examine complex structures such as the Abbey of Santa Maria a Mare are the non-need of in situ instrumentation of sensors, the absence of difficulties to reach structures or structural members and the independence of natural light sources [Park et al. 2007].

Data processing followed different steps:

1) Scan point filtering for cleaning bad data point clouds, mainly due to long distances to targets, uncertain positions of the points and intensity of reflectance, through the JRC Reconstructor v.3 software (Gexcel-Spin off company of the University of Brescia);

2) Alignment of each scan registration according to the reference system using the lterative Closest Point (ICP) algorithm. It iteratively applies a rigid roto-translation in one of the two clouds, considered to be mobile, so that overlap in the best possible way to another cloud, considered fixed [Barrile et al. 2017]. During the manual recording of the scans, the existence of three common points between each scan (fixed and mobile) has been required. The registration error has been calculated at $1 \mathrm{~mm}$. Given the large number of point cloud, the dense cloud has been decimated using a factor of subsampling equal to 10.
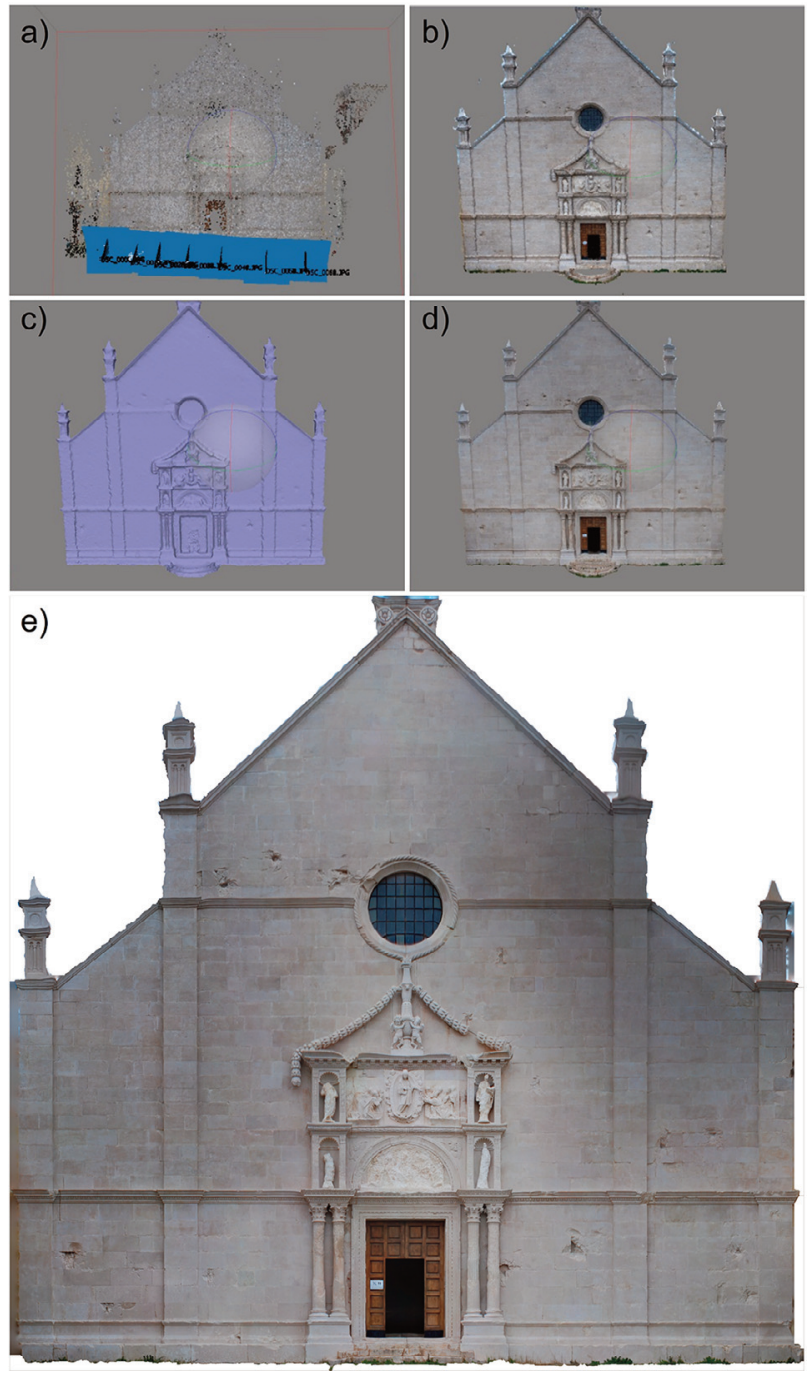

FIGURE 2. Example of Agisoft PhotoScan processing: positions taken by the camera (a), dense cloud (b), mesh (c), texture (d) and ortophoto (e).

3) Surface reconstruction through the "Basic mesh method".

4) Extraction of plants and sections for vector data (DXF format), photographic data (JPG format) and surface images (PLY and OBJ formats).

5) Production of high-resolution orthophotos using a Camera Canon 4D Mark 11 (20mp). About 4200 images have been acquired using the aperture priority mode and the manual exposure setting and ensuring a mean overlap of about 70\%. The Agisoft Photoscan software (Agisoft PhotoScan, http://www.agisoft.com/) has been used for data processing [Remondino and El-Hakim 2006, Remondino 2008]. The photogrammetric model was scaled using 40 ground control point (GCP) located on the floor and on the walls of the church. Each marker has been registered using a total station and the output has been reported using the reference system of Monte 

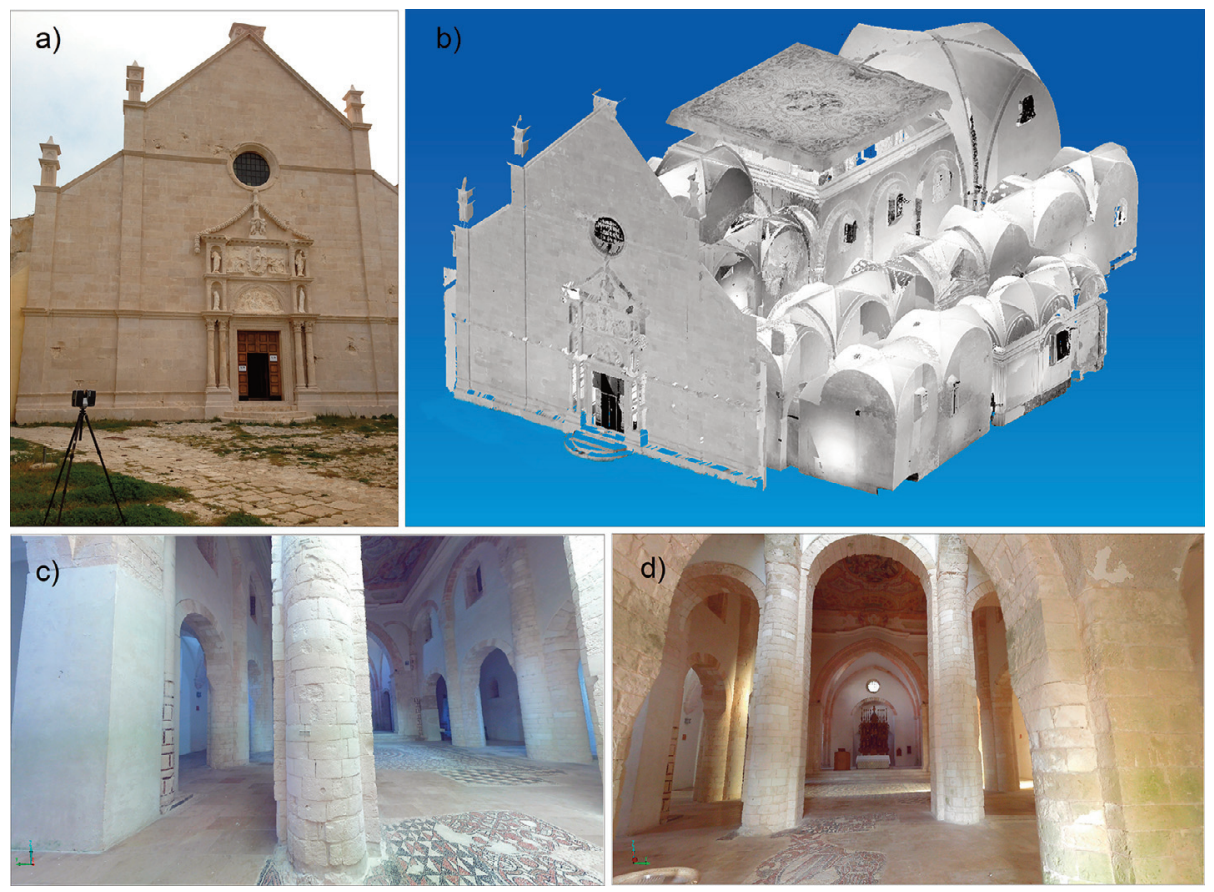

FIGURE 3. Laser scanner Focus 3D MS120 (FARO) (a), mesh visualization of the model (b), RGB visualization of the cloud points (c, d).

Mario/ltaly, zone 2 (EPSG: 3004). The model was generated using the "high alignment" (Figure 2a) (key point limit: 40.000, tie point limit: 4.000) and the "medium build dense cloud" settings (Figure $2 \mathrm{~b}$ ). After the generation of the dense cloud, the model was georeferenced using the GCP method obtaining a registration error of about $3 \mathrm{~mm}$. The mesh processing procedure (Figure 2c) has been realized using the commonly "multi-resolution model" routine based on automated algorithms in order to recognize and fit discontinuities on the model [Angelini and Portarena 2018]. The model then has been improved through the "optimization method" for rearranging and smoothing the nodes of triangles and the "decimation filter" for simplifying the model and generating a multi-resolution model. The texture mapping process (Figure $2 \mathrm{~d}$ ) has provided the parameterizing of the texture atlas trough the "Generic mapping mode" in order to create a texture as uniform as possible and the blending of low and high frequency components for overlapping images to avoid seam line problems through the "Mosaic blending mode". The last one process is based on the weighted average where the weights are a number of parameters including proximity of the pixel in question to the center of the image.

6) Data integration through the alignment and assimilation of laser scanner and photogrammetric point clouds considering the laser scanning coordinate system as reference.

A 3D model of the interior of the building and the external facade made up of approximately 18 million points was created. Figure 3 shows a three-dimensional view of the product of the point cloud conversion in meshes and some images obtained from the colorimetric overlay operation (RGB). The dot cloud was used to extract plants and sections in DXF format for vector data and TIFF for photographic data. Figure 4 displays the location of 11 cross sections and 8 longitudinal sections with respect to the main body of the building.

In Figure 5, the reflection section extrapolated from the 3D model with the application of orthophotos of the visible surfaces and the characterization of fractures,

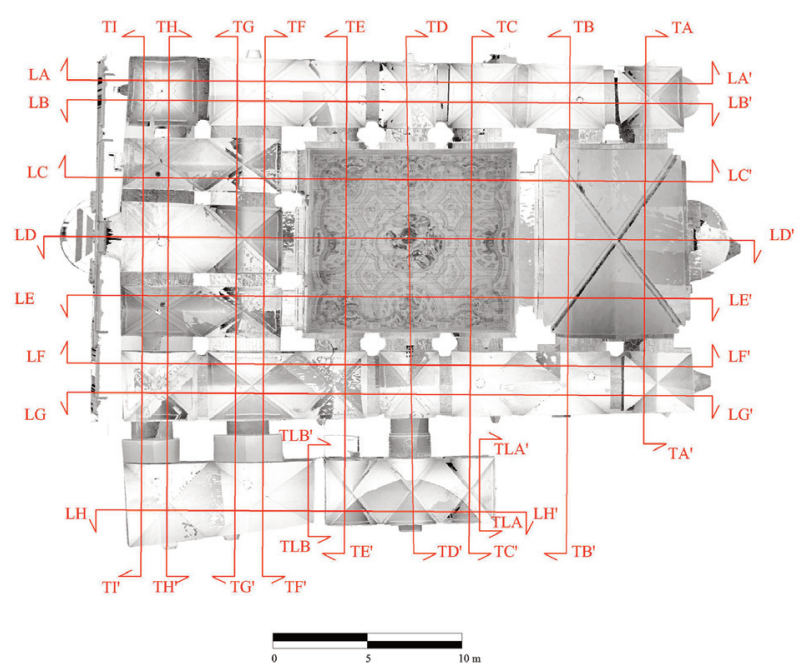

FIGURE 4. Location of the sections extrapolated by the point cloud. 


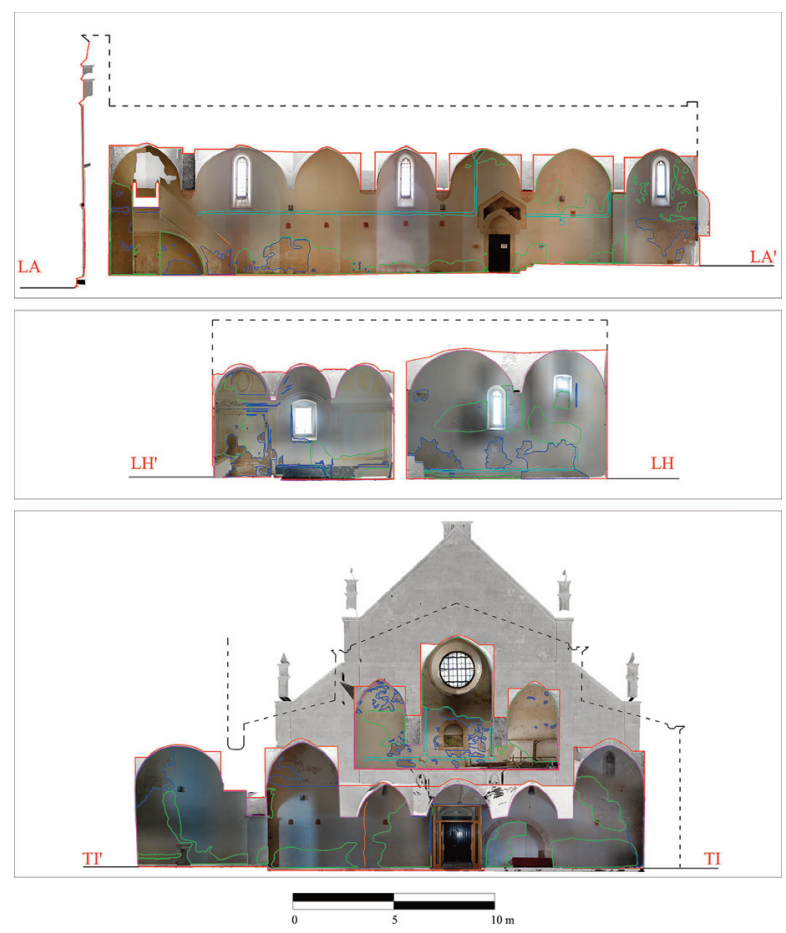

FIGURE 5. LA-LA ${ }^{1}$, LH-LH ${ }^{1}$ and TI-TI ${ }^{1}$ sections: reflection section extrapolated by the 3D model with application of the orthophotos of the visible surfaces and indication of anomalies (cutting plane in pink, detachments of plaster in dark blue, modern intervention in light blue, traces of humidity in green, fractures in orange, the section line in red)
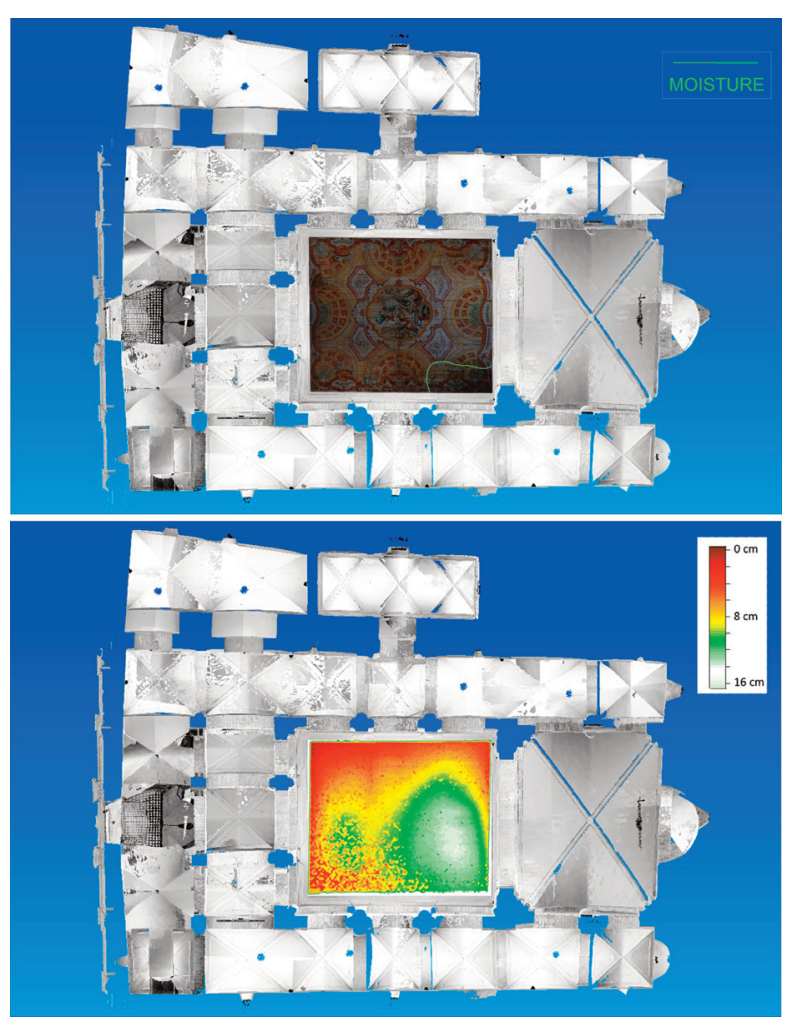

FIGURE 6. Orthophoto of the wooden ceiling located on a section of the 3D model with indication of anomalies (top) and model of elevation (bottom). traces of moisture, detachment of the surface, plaster and modern interventions on the foreground surfaces are reported for $\mathrm{LA}-\mathrm{LA} A^{1}, \mathrm{LH}-\mathrm{LH}^{1}$ e $\mathrm{Tl}^{-\mathrm{Tl}^{1}}$ sections.

Figure 6 depicts an orthophoto of the painted ceiling, its characterization and a surface elevation model located on the section of the three-dimensional model.

\subsection{GROUND PENETRATING RADAR (GPR) SURVEY}

The use of non-destructive investigation techniques at different scales can integrate moderately destructive tests and provide tools for verifying the conservation status of any masonry work. In this context, the use of the Ground Penetrating Radar (GPR) technique has proven to be a rapid, effective and non-invasive on-site survey method for the identification of cracks and voids, wall textures, detachments, inclusions of different materials, structural elements and humidity in the walls [Ranalli et. al 2004, Gonzalez-Drigo 2008, Hemeda 2013, Pérez-Gracia 2009, Masini and Saldovieri 2011, Kadioglu et al. 2013, Catapano et al. 2017, Masini and Saldovieri 2017]. The GPR is an electromagnetic impulsive method much suited for shallow depth investigations, as it can supply subsurface profiles grouped in vertical radar sections [Goodman and Piro 2013]. During data acquisition, the transmitter-receiver antenna is moved along the surface, signals are sent into the ground and echoes are returned from targets in the ground within a few meters. According to the media impedance and to their heterogeneity, the radar pulse can be reflected towards the surface or else it can be attenuated and diffused, hence quickly totally dissipated. When reflected echoes emerge, the received signal can be correlated with the transmitted one and the delay of arrivals is a function of velocity [Cozzolino et al. 2018b].

The instrumentation used in this work was the IDS georadar RIS-K2 with a TRMF (200-600 MHz) antenna and a $1200 \mathrm{MHz}$ high-resolution antenna. Data were processed using the GPR-SLICE 7.0 software [Goodman, 2014]. Technically, data acquisition took place on lines where instrumental readings were executed in continuous mode. The standard profiles were processed implementing band pass filters, noise reduction filters and gain procedure [Conyers and Goodman 1997, Goodman and Piro 2013]. In this case, for each surveyed area, several parallel profiles were acquired forming a grid pattern to verify the extent and size of the buried targets. Thus, a 3D data matrix was obtained underneath the investigated surface from which the horizontal sections (time slices) were extracted at different depths in which the various hidden structural features are displayed in different colors. 
Five areas were investigated on the floor using a multifrequency antenna (200-600 MHz). In total, 37 survey profiles were acquired for a total length of $445.7 \mathrm{~m}$. Figure 7 shows the horizontal slices relative to $0.5 \mathrm{~m}$ in depth positioned on the floor plan of the building. Finally, using a $1200 \mathrm{MHz}$ antenna, a high-resolution survey was carried out on the left wall of the building and on the inner wall of the entrance to verify the presence of moisture inside the masonry. Figure 8 reports the slice relative to $0.20 \mathrm{~m}$ in depth on LA-LA' and $\mathrm{Tl}^{1} \mathrm{Tl}^{1}$ sections.

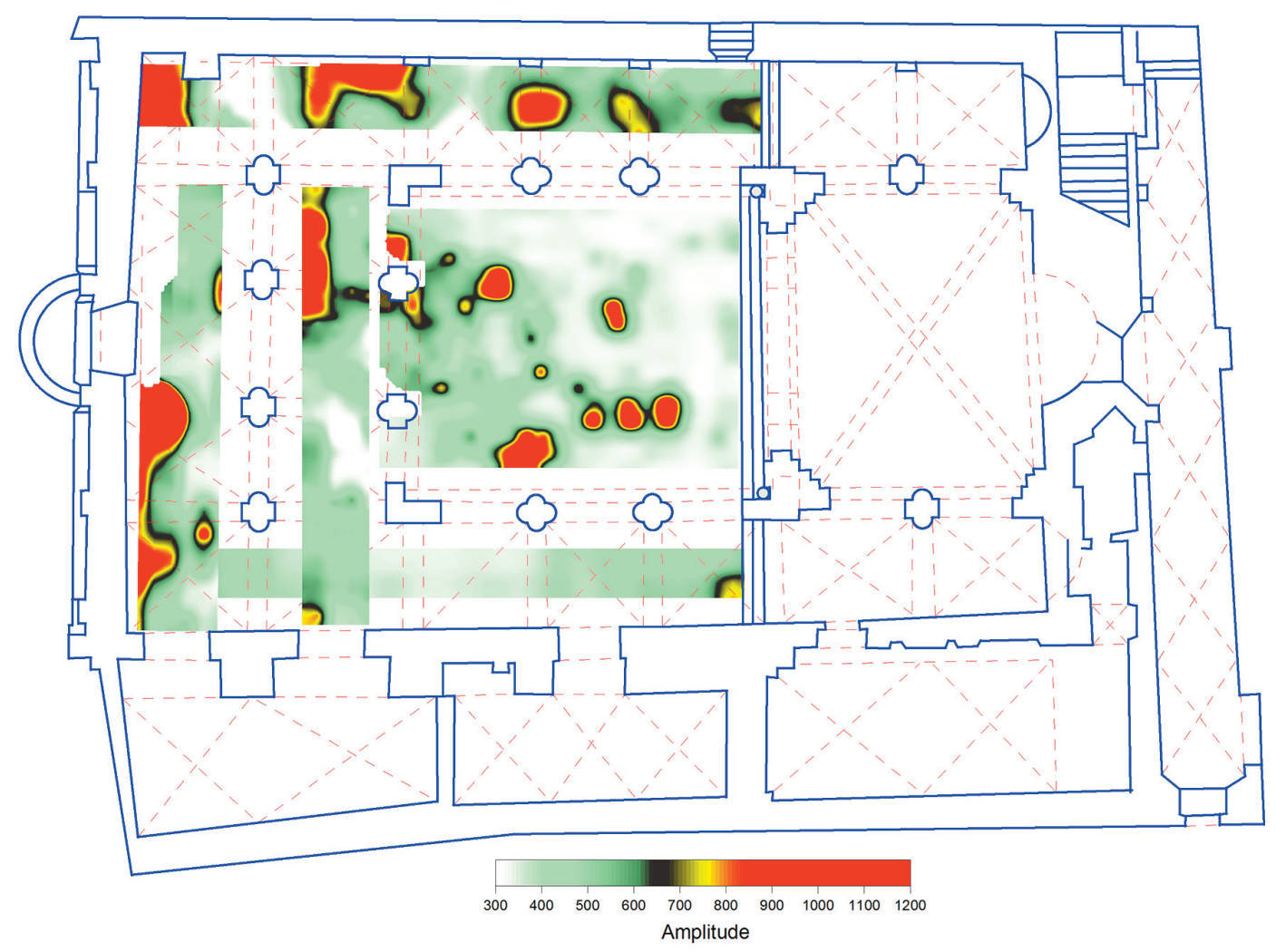

FIGURE 7. Horizontal slice relative to $0.5 \mathrm{~m}$ in depth.

\section{RESULTS AND DISCUSSION}
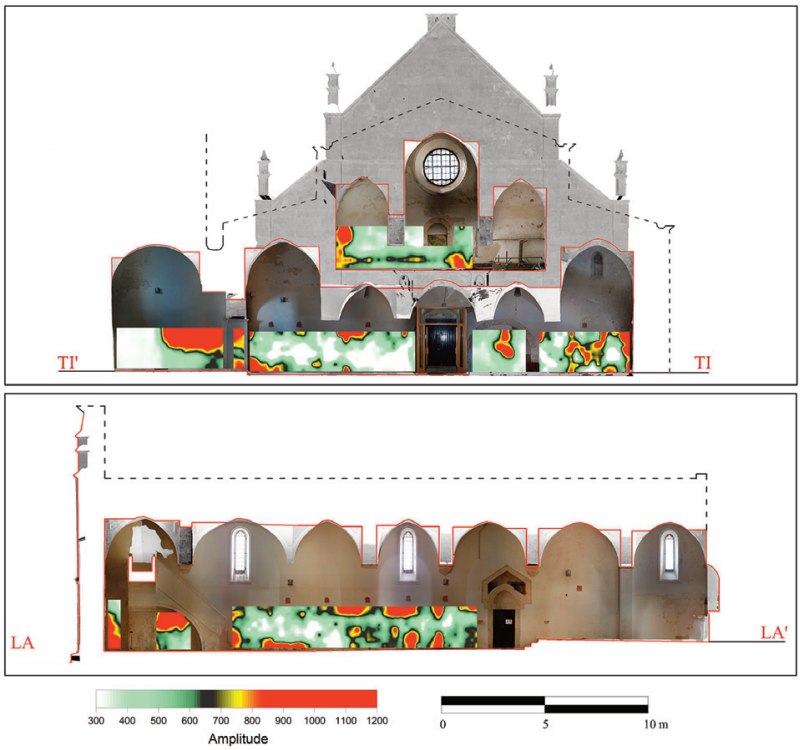

FIGURE 8. Vertical slice relative to $0.20 \mathrm{~m}$ in depth.
The analysis of the results clearly shows a level of advanced degradation of the interior of the building perceived by the presence, on each analyzed wall, of substantial moisture traces often associated with considerable separations of plasterwork, swelling, mold appearance and blasting of paintings. In particular, a detail evaluation of any sign of deterioration of the building was achieved, whose nature, extension and location can simply be drawn graphically from the processed images.

The most critical conditions were found in sections near the outer walls (Sections: LA-LA', left side; LH-LH', right side; $\mathrm{Tl}_{-} \mathrm{Tl}$, wall of the entrance) (Figure 5) where the phenomena of decay are more pronounced. The GPR surveys carried out on the inner wall of the entrance (ground floor and loggia) and on the left wall of the building confirm the presence of water within the analyzed surfaces. This is evidenced by the total absorption of electromagnetic signals found in radargrams and in the 
obtained parallel slice to the walls (Figure 8). In the latter, in the spots indicated by the green-white colors, low signal amplitudes were detected coinciding with obvious traces of moisture on the surface.

Given the extent of degradation events, it can be assumed that water infiltration can be mainly due to the absorption and diffusion of rainwater through external surfaces constructed with non-water-repellent porous limestone blocks. Probable penetration through nontightened openings and non-watertight or deteriorated covers should be added to these phenomena.

With regard to the cracking framework of the monument, it was possible to document vertical lesions concerning the two columns of the entrance (Sections: TE-TE ${ }^{l}$ and TF-TFl) and a column of the left nave (LB-LB' section), the frames at the base of the decorated wooden ceiling (Sections: LC-LCl, and TE-TEl) and some walls (Sections: LD-LD', LF-LF', TA-TA', TE-TE ${ }^{1}$ and Tl-Tl'). In order to evaluate the evolution of deformations, active movements and rotations, it would be desirable to continuously monitoring lesions and to program interventions that increase the resistance of the structure, especially in view of possible external actions and strains such as seismic ones.

Finally, the laser scanner survey has enabled a precise geometric determination and an accurate morphological knowledge of the building. In detail, some elements that could be attributed to constructive defects and/or structural interventions carried out in recent times and/or to deformations caused by natural events (seismic movements and substrate settlements) may have emerged. Some sections (TB-TB', TC-TC' ${ }^{1}$ TF-TFl, TG-TG $^{1}, \mathrm{TH}^{1} \mathrm{TH}^{1}$ and $\mathrm{Tl}^{-\mathrm{Tl}}$ ) show a non-verticality of the walls of the chapel located to the right of the church (deviation from the vertical axis between 0.1 and $0.24 \mathrm{~m}$ ) and the outer wall of the left nave (deviation from the vertical axis between $0,1 \mathrm{~m}$ and $0.16 \mathrm{~m}$ ) (Figure 9). In particular, due to the presence of major fractures in the masonry of the rooms above the right aisle, such irregularities could favor, in case of seismic stresses, the right-tipping mechanisms of the right body.

As regards the wooden ceiling, some sections (LB-LB', LC-LC', LD-LD', LE-LE', LF-LF', TC-TC', TD-TD', TE-TE', T5-T5 and ${ }^{1} 6-\mathrm{T}^{1}$ ) indicate a deviation from the horizontal axis between 0 and $0.16 \mathrm{~m}$, concentrated above all on the left side. The digital elevation model extrapolated from the point cloud (Figure 6) shows variations in detected altitudes, differences partially coinciding with a visible moisture trace on the surface. For this anomaly, deform metric monitoring of active movements would be desirable in order to assess the evolution of the phenomenon.
Finally, numerous irregularities and depressions emerged in the paved floor (especially near the mosaic), a slope from the left to the right side of the building (0.24$0.26 \mathrm{~m})$ and from the central square to the entrance $(0-0.09 \mathrm{~m})$ (Sections $\mathrm{L} 1-\mathrm{L}^{1}$ and $\left.\mathrm{L} 2-\mathrm{L} 2^{\mathrm{l}}\right)$. GPR analysis has not shown any anomaly that can be attributed to cavities or voids but only the presence of some elements that are probably attributable to structural elements prior to the present construction. In the central nave area, the bonding materials used in the restoration of the mosaic heavily disturbed the investigations.

The non-invasive analysis carried out at the Abbey of Santa Maria a Mare has allowed to identify a detailed picture about the state of health of the building. The identified critical damage elements could be related to the poor maintenance of the structure and to the natural phenomena of degradation trigged over time. Given the extent of the cracking of walls and columns, the conspicuous presence of humidity, the irregularity of the structure in plan and height, the building could be vulnerable and suffering damage and collapse when a seismic event occurs. In order to safeguard public safety and protect the monument from its destruction, it is necessary to carry out structural analyzes defining the seismic vulnerability.

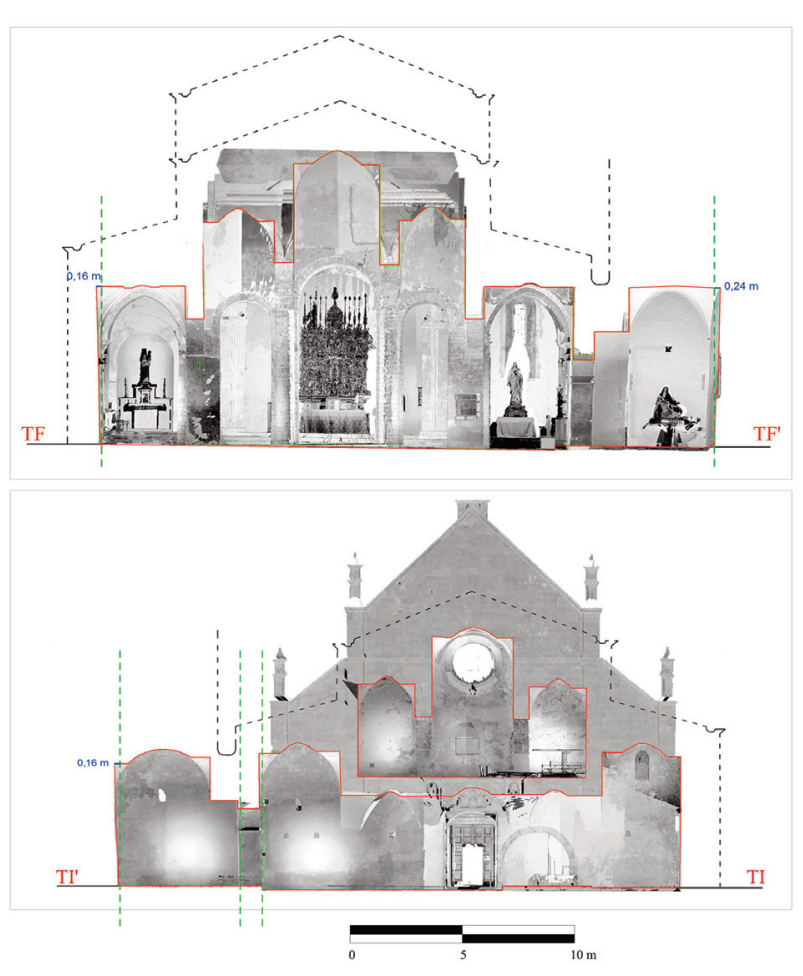

FIGURE 9. Deviation from the vertical axis of the lateral walls (TF-TF ${ }^{\mathrm{I}}$ and $\mathrm{TI}-\mathrm{TI}^{\mathrm{I}}$ sections). 
Simplifying the seismic-resistant structure through a calculation model in order to carry out specialized analyzes, the damage foreseen according to the intensity of the ground acceleration due to the earthquake should be provided in probabilistic terms. The results of the investigations have provided good elements to stimulate and promote the systematic planning of diagnostic, consolidation and restoration projects.

Acknowledgements. The work was realized in collaboration with the Superintendence of Archeology, Arts and Landscape for the provinces of Foggia and Barletta-Andria-Trani and with the support of the Banca del Monte Foundation. Special thanks to Dr. Roberto Gabrielli who has provided the metric instrumentations for this research and to Pasquale Galatà that has participated to data acquisition and processing of the metric survey.

\section{REFERENCES}

Angelini A. (2018). Tecniche di rilevamento e metodi di rappresentazione per l'Architettura Rupestre, BAR International Series, vol. S2889, Oxford.

Angelini A. and D. Portarena (2018). Advice for archaeological survey with recent technologies, in ACTA IMEKO, 7(3), 42- 1.

Barrile V., G. M., Meduri and G. Bilotta (2009). Laser scanner surveying techniques aiming to the study and the spreading of recent architectural structures, in Proceedings of the 2nd WSEAS International Conference on Engineering Mechanics, Structures and Engineering Geology, EMESEG '09: "Recent Advances in Engineering Mechanics, Structures and Engineering Geology”, Rodos, Greece, July 22-24, 25-28.

Barrile V., G. Bilotta, G.M. Meduri, D. De Carlo and A. Nunnari (2017). Laser Scanner technology, groundpenetrating radar and augmented reality for the survey and recovery of the artistic, archaeological and cultural heritage, in The ISPRS Annals of the Photogrammetry, Remote Sensing and Spatial Information Sciences, Volume IV-4/W4, 2017 4th International GeoAdvances Workshop, 14-15 0ctober 2017, Safranbolu, Karabuk, (Turkey), 123-127.

Carbonara G. (Editor) (2005). Atlante del Restauro, UTET, Perugia, 17 (1), 399.

Catapano I., G. Ludeno, F. Soldovieri, F. Tosti and G.Padeletti (2017). Structural assessment via ground penetrating radar at the Consoli Palace of Gubbio (Italy), in Remote Sens., 10:45.

Cifani G., Lemme A., Podestà S. (Editors) (2005). Beni monumentali e terremoto. Dall'emergenza alla ricostruzione, DEI, Tipografia del Genio Civile, Roma.

Conyers L.B. and Goodman D. (1997). Ground Penetrating Radar. An introduction for archaeologists. AltaMira Press, Walnut Creek, California.

Cozzolino, M., A. Di Meo, V. Gentile and P. Mauriello (2018a). Alcuni aspetti tecnologici per la salvaguardia del patrimonio culturale: il contributo dell'ITAB-CNR nello studio della vulnerabilità dell'Abbazia di Santa Maria a Mare alle Isole Tremiti, in Atti del Convegno "Restauro e Terremoto. I Beni Culturali della Capitanata”, 2 febbraio 2017, Auditorium Santa Chiara, Foggia, Edipuglia, Bari. Cozzolino M., E. Di Giovanni., P. Mauriello., S. Piro and D. Zamuner (2018b). Geophysical Methods for Cultural Heritage Management, Springer (Ed), Berlin, (Germany).

Fiani M. and N. Siani (2005). Comparison of Terrestrial Laser Scanners in Production of DEMS for Cetara Tower, in The CIPA International Archives for Documentation of Cultural Heritage, XX-2005, 277281.

Gonzalez-Drigo R., V. Pérez-Gracia, D. Di Capua and L. G. Pujades (2008). GPR survey applied to Modernista buildings in Barcelona: the cultural heritage of the College of Industrial, in Engineering. Journal of Cultural Heritage, 9,196-202.

Goodman D. and S. Piro (2013). GPR Remote sensing in Archaeology. Springer (Ed), Berlin, (Germany).

Goodman D. (2014). GPR-SLICE v7.0 Manual, from http://www.gpr-survey.com, January/2014.

Hemeda S. (2012). Ground penetrating radar investigations for architectural heritage preservation of the Habib Sakakini Palace Cairo Egypt, in Int. J. Conserv. Sci., V3 (3), 153-162.

Ioannidis C., N. Demir., S. Soile and M. Tsakiri (2005). Combination of Laser Scanner Data and Simple Photogrammetric Procedures for Surface Reconstruction of Monuments, in The CIPA International Archives for Documentation of Cultural Heritage, XX-2005, 372-377.

Kadioglu S., Y.K. Kadioglu., I. Catapano and F. Soldovieri (2013). Ground penetrating radar and microwave tomography for the safety management of a cultural heritage site: Miletos Ilyas Bey Mosque (Turkey), in J Geophys Eng 10(6):064007.

Masini N. and F. Soldovieri (2011). Special Issue on "Integrated non-invasive sensing techniques and geophysical methods for the study and conservation of architectural, archaeological and artistic heritage”, in J Geophys, Eng. 
Masini N. and F. Soldovieri (2017). Cultural Heritage sites and sustainable management strategies, in Masini N., Solodovieri F. (eds), Sensing the past. From artifact to historical site, Springer, Basel.

Murtiyoso A. and P. Grussenmeyer (2017). Documentation of heritage buildings using Close-range uav images: dense matching issues, comparison and case studies, in The Photogrammetric Record, 32(159), 206-229.

Park H.S., H.M. Lee, H. Adeli and I. Lee (2007). A New Approach for Health Monitoring of Structures: Terrestrial Laser Scanning, in Computer-Aided Civil and Infrastructure Engineering, 22, 19-30.

Pérez-Gracia V., O. Caselles., J. Clapés, R. Osorio, J. A. Canas and L. G. Pujades. (2009a). Radar exploration applied to historical buildings: A case study of the Marques de Llió palace, in Barcelona (Spain), in Engineering Failure Analysis, 16,1039-1050.

Ranalli D., M. Scozzafava and M. Tallini (2004). Ground penetrating radar investigations for the restoration of historic buildings: the case of the Collemaggio Basilica, (L'Aquila, Italy), in J. Cult Herita, 5, 9199.

Remondino F. and El-Hakim S. (2006). Image-based 3D modelling: a review, in The Photogrammetric Record, 21, 269-291.

Remondino F., S. F. El-Hakim., A. Gruen and L. Zhang (2008). Turning images into 3-D models, in IEEE Signal Processing Magazine, 25 (4), 55-65.

Remondino F. and S. Campana (2014). 3D Recording and Modelling in Archaeology and Cultural Heritage. Theories and best practices, in 3D Recording and Modelling in Archaeology and Cultural Heritage. Theories and best practices (Remondino F. and Campana S. Editors), Archaeopress.

Selbesoglu M. 0., Bakirman T. and O. Gokbayrak (2016). Deformation measurement using terrestrial laser scanner for cultural heritage, in The International Archives of the Photogrammetry, Remote Sensing and Spatial Information Sciences, 3rd International GeoAdvances Workshop, 16-17 October 2016, Istanbul, Turkey, XLII-2/W1, 89-93.

Vatan, M., Selbesoglu, M.O. and B. Bayram (2009). The use of 3D laser scanning technology in preservation of historical structures, in Wiadomości Konserwatorskie, 659-669. 